\title{
Avaliação Morfométrica de Eqüinos da Raça Mangalarga Marchador: Medidas Lineares ${ }^{1}$ \\ Grasiele Coelho Cabral ${ }^{2}$, Fernando Queiroz de Almeida ${ }^{3}$, Célia Raquel Quirino4, Luís Fernando Batista Pinto ${ }^{5}$, Edson Mauro Santos ${ }^{6}$, Anderson Corassa ${ }^{5}$
}

\begin{abstract}
RESUMO - Objetivou-se com o presente trabalho avaliar o crescimento de potros da raça Mangalarga Marchador por meio de suas medidas lineares. Foram mensurados 98 potros, sendo 55 machos e 43 fêmeas, ao nascimento e a cada 30 dias até completarem 12 meses de idade. Os pais e as mães dos potros foram mensurados para obtenção dos valores médios das medidas lineares estudadas nos animais adultos. Os valores das medidas corporais dos animais foram submetidos à análise de variância e o modelo estatístico incluiu os efeitos de sexo, local, manejo nutricional, rebanho, mês e ano de nascimento. As características de conformação estudadas não foram influenciadas pelos efeitos de sexo, rebanho, região, manejo nutricional, mês e ano de nascimento. A medida de altura na cernelha apresentou reduzida variação, passando de $61,6 \%$ da média à idade adulta, ao nascimento, para 88\% da média à idade adulta, aos 12 meses, nos machos, e de 63,2\% da média à idade adulta, ao nascimento, para 90\% da média à idade adulta, aos 12 meses, nas fêmeas. De forma similar, a altura na garupa passou de 63,3\% da média à idade adulta, ao nascimento, para 89\% da média à idade adulta, aos 12 meses, nos machos e de 64,1\% da média à idade adulta, ao nascimento, para 91,1\% da média à idade adulta, aos 12 meses, nas fêmeas. O comprimento do corpo dos potros apresentou valores de 68,1; 112,6 e 127,1 cm nos machos e de 68; 111,6 e 128,3 cm nas fêmeas, ao nascimento, 6 e 12 meses, respectivamente. Em relação à idade adulta, os valores observados para comprimento do corpo foram 43,3; 71,6 e 86,6\%, nos machos, e 45,5; 74,7 e 85,8\%, nas fêmeas, ao nascimento, 6 e 12 meses de idade, respectivamente.
\end{abstract}

Palavras-chave: crescimento, mensuração, potros

\section{Morphometric Evaluation of Mangalarga Marchador Horses: Linear Measures}

\begin{abstract}
The present work aimed to evaluate foals growth of the Mangalarga Marchador breed, by linear measures. Ninetyeight foals, 55 males and 43 females were measured at birth and at each 30 days up to 12 months age. Results of body measures were submitted to analysis of variance and statistical model includes effects of sex, local, nutritional management, herd, month and year of birth. Conformation characteristics studied were not influenced by the effects of sex, herd, nutritional management, month and year of birth. In relation to height in the withers and in the hip measures, it was observed small variation, from 61.6 and $63.3 \%$ of mature age, at birth, from 88 to $89 \%$ of mature age, at $12^{\text {th }}$ month of age, for males and from 63.2 and $64.1 \%$ of mature age, at birth, from 90.0 to $91.1 \%$ of mature age, at $12^{\text {th }}$ month of age, for females. Values of body length of foals were of $68.1,112.6$ and $127.1 \mathrm{~cm}$ for males and $68.0,111.6$ and $128.3 \mathrm{~cm}$, for females, at birth, $6^{\text {th }}$ month and $12^{\text {th }}$ month of age, respectively. In relation to mature age, the observed values of body length were $43.3,71.6$ and $86.6 \%$, for males and $45.5,74.7$ and $85.8 \%$, for females, at birth, $6^{\text {th }}$ month and $12^{\text {th }}$ month of age, respectively.
\end{abstract}

Key Words: foals, growth, measurement

\section{Introdução}

O desenvolvimento de potros pode ser avaliado por diversos parâmetros, sendo freqüentes a pesagem e a mensuração da altura na cernelha e do comprimento do corpo. Segundo Jordão \& Camargo (1950), a altura dos potros ao nascimento representa cerca de $60 \%$ da altura adulta e o crescimento em altura de potros é muito intenso até um ano de idade, sendo o primeiro mês pós-nascimento o período de maior intensidade. Santos (1989) observou que a altura na cernelha, entre todas as medidas lineares, é uma das mais seguras, por mostrar menores variações decorrentes do instrumento de mensuração ou dos erros cometidos pelo mensurador.

O padrão racial definido pela Associação Brasileira de Criadores do Cavalo Mangalarga Marchador

\footnotetext{
${ }^{1}$ Parte da Dissertação do primeiro autor apresentada ao Programa de Pós-graduação em Zootecnia da UFRRJ. Projeto de pesquisa financiado pela FAPERJ.

2 Zootecnista. Mestre em Zootecnia - UFRRJ - Seropédica - RJ (g.ccabral@bol.com.br).

3 Professor Adjunto. Instituto de Veterinária - UFRRJ (falmeida@ufrrj.br).

Correspondência: DMCV-IV-UFRRJ. BR 465, km 7, Seropédica, RJ. 23890-000

4 Professor Associado - LMGA-CCTA-UENF - Campos dos Goytacazes - RJ (crq@uenf.br)

${ }^{5}$ Discente de graduação em Zootecnia. Bolsista de Iniciação Científica FAPERJ.

${ }^{6}$ Discente de graduação em Zootecnia. Bolsista de Iniciação Científica PIBIC/CNPq - UFRRJ.
} 
- ABCCMM, que desde 1949 mantém os livros de registros dos eqüinos da raça, baseia-se na aparência externa e na mensuração da altura na cernelha dos animais, nos quais a presença do andamento marchado é obrigatória e sua ausência é desclassificatória. Os animais inscritos nos Livros de Registros Definitivos devem possuir ascendência em reprodutores da raça Mangalarga Marchador e apresentar a altura na cernelha entre 1,47 e 1,57 m, nos machos, e 1,40 e 1,54 m, nas fêmeas (ABCCMM, 1992).

Barbosa (1993), avaliando animais adultos da raça Mangalarga Marchador, observou valores médios de altura na cernelha de 1,50 e 1,45 m, para machos e fêmeas campeões, respectivamente. As medidas de menor variação foram a largura da cabeça e o perímetro da canela e as de maior variabilidade, o comprimento do dorso-lombo e o perímetro torácico.

Este trabalho foi conduzido com o objetivo de avaliar as medidas lineares de eqüinos da raça Mangalarga Marchador, dos potros, do nascimento aos 12 meses de idade, e dos progenitores.

\section{Material e Métodos}

O experimento foi conduzido no período de agosto de 2000 a março de 2002 em criatórios de cavalos da raça Mangalarga Marchador, na Região Serrana e Metropolitana do Estado do Rio de Janeiro. Foram utilizados 98 potros, sendo 55 machos e 43 fêmeas, os quais foram mensurados ao nascimento e a cada 30 dias até os 12 meses de idade. Os potros eram filhos de 14 garanhões diferentes, representantes das mais diversas linhagens da raça Mangalarga Marchador.

O manejo alimentar dos animais foi similar em seis haras da Região Serrana. Do nascimento ao desmame, os potros permaneceram com as éguas mantidas em pastagens de capim-coastcross (Cynodon dactylon) e estrela-africana (Cynodon plectostachyus) e suplementadas com capim-elefante (Pennisetum purpureum) picado e ração comercial. Após o desmame, os potros receberam capim elefante picado ad libitum e ração comercial em quantidades diárias de, aproximadamente, $1 \mathrm{~kg}$. No haras da Região Metropolitana, em Jesuítas, RJ, durante algumas horas da manhã e da tarde, enquanto as éguas recebiam suplementação, os potros, desde o nascimento, ficavam separados em um potreiro coletivo, onde recebiam feno de alfafa (Medicago sativa) ad libitum. Após o desmame, estes recebeiam capimelefante picado ad libitum e ração comercial em quantidades diárias de $1 \mathrm{~kg}$, aproximadamente. Os animais receberam sal mineral no pasto e foram vermifugados a cada três meses.

O desenvolvimento corporal dos potros foi avaliado segundo Camargo \& Chieffi (1971), Brito (1990), Barbosa (1993) e Thompson (1995), por intermédio das seguintes medidas de altura: cernelha, garupa, costado; medidas de comprimento: cabeça, pescoço, espádua, dorso-lombo, garupa e corpo; medidas de largura: cabeça, peito e ancas; medidas de distância: codilho-joelho, joelho-boleto, soldra-jarrete, jarreteboleto, codilho-solo, ponta da espádua-boleto; medidas de perímetro: antebraço, joelho, canela, boleto e toráx. Os pais e as mães dos potros foram mensurados para obtenção dos valores médios das medidas lineares estudadas nos animais adultos. A média dos machos e das fêmeas adultas foi utilizada como base de cálculo dos valores percentuais dos potros em relação à idade adulta. As medidas foram obtidas utilizando-se hipômetro e fita métrica. Os animais foram mensurados sempre do lado direito do corpo, posicionados em estação, apoiados sobre os quatro membros ao chão na posição correta dos aprumos, sobre piso de cimento, menos irregular possível e sem declividade.

Foi realizada a análise de consistência dos dados e a estatística descritiva das características estudadas utilizando o procedimento MEANS, FREQ do programa SAS (SAS, 1996). Os resultados foram submetidos à análise de variância e os efeitos de sexo, local de criação, manejo nutricional, rebanho, mês e ano de nascimento dos potros, testados dentro de cada idade. Com relação aos dados dos animais adultos, foi feita análise de variância e testado o efeito de sexo.

\section{Resultados e Discussão}

Os valores médios, desvios-padrão e percentuais em relação à idade adulta da altura na cernelha, na garupa e do costado de eqüinos, de ambos os sexos, do nascimento aos 12 meses de idade e dos animais adultos estão descritos na Tabela 1 .

Os valores médios de altura na cernelha foram de 93,$4 ; 122,8$ e $133,3 \mathrm{~cm}$ para os machos e de 92,9 ; 121,5 e 132,1 cm para as fêmeas, ao nascimento, aos 6 e aos 12 meses de idade, respectivamente. Esses valores correspondem a ganho médio de 20; 9,0; 6 e $4,6 \mathrm{~cm}$, respectivamente, no primeiro, segundo, terceiro e quarto trimestres, concordando com Santos (1989), quando cita que o ganho médio em altura de potros da raça Brasileiro de Hipismo foi maior nos

R. Bras. Zootec., v.33, n.4, p.989-1000, 2004 


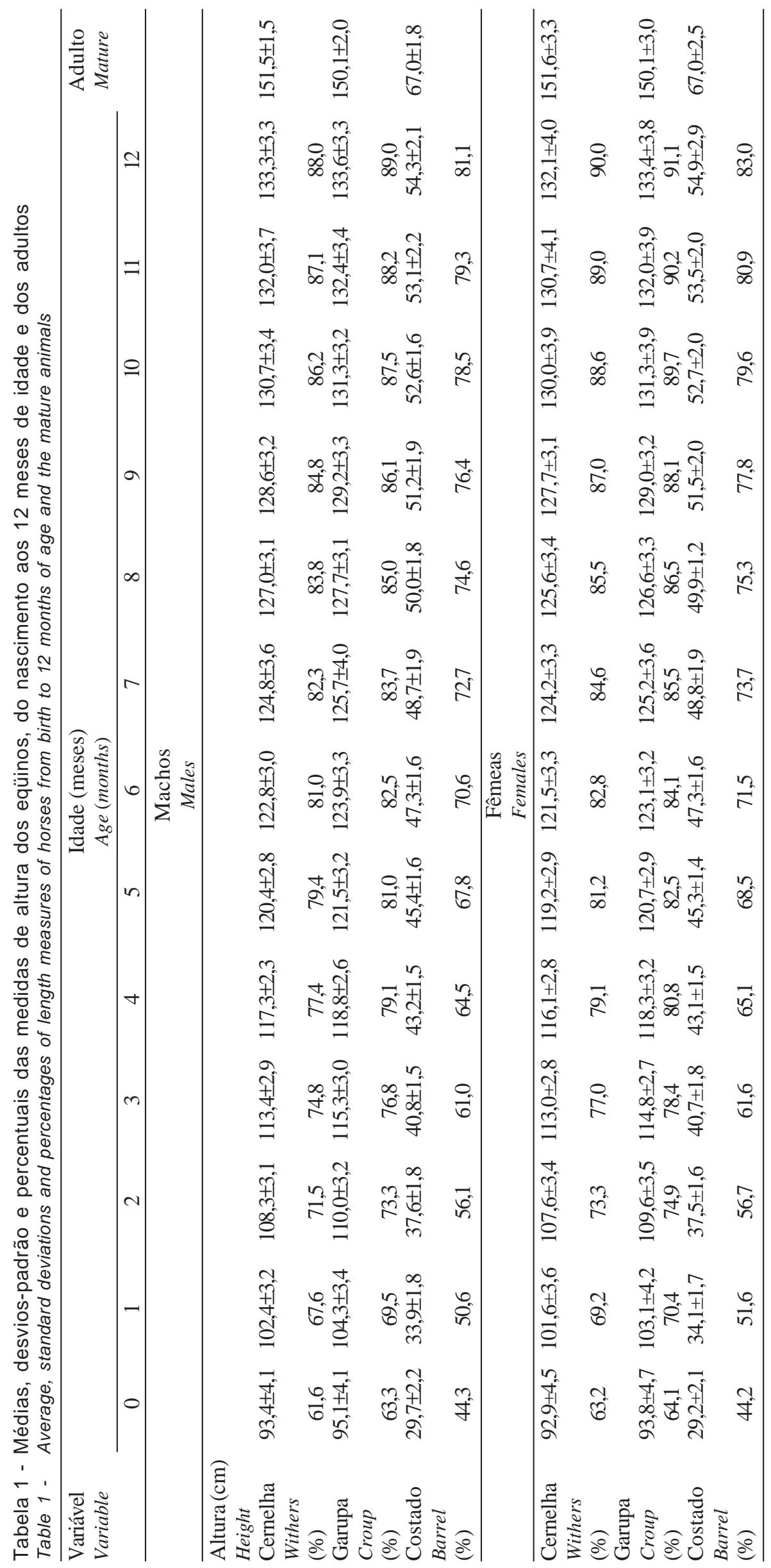


três primeiros meses, comparativamente ao ganho médio total dos nove meses posteriores.

Os valores médios obtidos para a medida de altura na garupa são muito parecidos com os de altura na cernelha, apesar de serem, em média, 1 a 2 cm maiores, sendo de 95,1; 123,9 e 133,6 cm para os machos e de 93,8; 123,1 e 133,4 cm para as fêmeas, ao nascimento, aos 6 e aos 12 meses de idade, respectivamente. Reed \& Dunn (1977) observaram que, até os 12 meses de idade, os machos apresentaram maior velocidade de crescimento para altura na cernelha, enquanto, nas fêmeas, a altura na garupa apresentou maior crescimento no mesmo período. Thompson (1995), estudando o crescimento de potros da raça Puro Sangue Inglês, relatou que a taxa de crescimento em altura na garupa é similar à na cernelha, porém maior em 2 a $3 \mathrm{~cm}$. Isso demonstra que os potros nascem com a garupa mais alta que a cernelha, porém esta última apresenta maior crescimento, com maiores valores à idade adulta.

As medidas de altura na cernelha e na garupa apresentaram pequena variação do nascimento aos 12 meses de idade e um percentual em relação à idade adulta que variou de 61,6 e $63,3 \%$ ao nascimento para 88,0 e $89,0 \%$ aos 12 meses, nos machos, e de 63,2 e $64,1 \%$ ao nascimento para 90,0 e $91,1 \%$ aos 12 meses, nas fêmeas. Segundo Jordão \& Camargo (1950), a altura dos potros ao nascimento representa cerca de $60 \%$ da altura adulta e o crescimento em altura de potros é muito intenso até um ano de idade, sendo o primeiro mês pós-nascimento o período de maior intensidade.

Hintz et al. (1979) observaram valores para altura na cernelha de 83 e 90\%, aos 6 e aos 12 meses, respectivamente, em potros Puro Sangue Inglês. Estes valores são semelhantes aos obtidos no presente estudo. Apesar da pequena variação, essas medidas são importantes na avaliação do crescimento, pois são parâmetros de desclassificação para o registro definitivo na raça Mangalarga Marchador.

Os valores médios observados para a altura do costado foram de 29,7; 47,3 e 54,3 cm nos machos e 29,2; 47,3 e 54,9 cm nas fêmeas, ao nascimento, aos 6 e aos 12 meses, respectivamente. Isso corresponde a valores percentuais da média à idade adulta de 44,3; 70,6 e 81,1\% nos machos e de 44,2; 71,5 e 83\% nas fêmeas. Esses valores demonstram que a altura do costado apresenta grande variação do nascimento aos 12 meses de idade, tanto nos machos quanto nas fêmeas.

A altura do costado é uma medida de grande importância, pois, juntamente com a medida de perí- metro torácico, fornece dados sobre a profundidade torácica, que é bastante considerada pelos árbitros no momento do julgamento de morfologia. Todavia, poucos dados são encontrados na literatura a respeito da altura do costado. Rezende (1984) observou valores médios de $58 \mathrm{~cm}$ para a altura do costado, em potros da raça Mangalarga Marchador aos 12,7 meses de idade, superando os valores dos machos e das fêmeas, aos 12 meses de idade, observados no presente estudo.

Os valores médios, desvios-padrão e percentuais, em relação à idade adulta, do comprimento da cabeça, do pescoço, da espádua, do dorso-lombo, da garupa e do corpo, dos machos e das fêmeas, do nascimento aos 12 meses e dos animais adultos, podem ser observados na Tabela 2.

Os valores do comprimento da cabeça foram de 32,2; 45,6 e 50,5 cm, nos machos e de 31,2; 45,6 e 49,5 cm, nas fêmeas, ao nascimento, aos 6 e aos 12 meses de idade, respectivamente. Os valores médios à idade adulta foram 57,7 e 56,7 cm, nos machos e nas fêmeas, respectivamente. Zamborlini (1996) observou valores de 58 e 57 cm, respectivamente, para machos e fêmeas adultos da raça Mangalarga Marchador, semelhantes aos de 58 e $57 \mathrm{~cm}$ obtidos para machos e fêmeas, respectivamente, por Barbosa (1993), em animais adultos da mesma raça.

O comprimento da cabeça é uma variável importante, pois é na cabeça que se avalia a expressão racial dos animais. Uma cabeça de comprimento desproporcional ao corpo pode descaracterizar o animal racialmente, mesmo que ele possua ótima conformação das outras partes do corpo. De acordo com Borton (1979), a cabeça é a primeira parte a ser observada no cavalo e deve ser atrativa, leve e proporcional ao tamanho do corpo.

Os valores observados para o comprimento do pescoço foram 32,5; 51,5 e 54,9 cm, nos machos, e 32,3; 50,4 e 55 cm, nas fêmeas, ao nascimento, aos 6 e 12 meses de idade, respectivamente. Os animais adultos apresentaram valores médios de 66,9 e 63,3 cm, para machos e fêmeas, respectivamente. Estes valores foram superiores aos observados por Zamborlini (1996) (61 e $63 \mathrm{~cm}$ ) e por Barbosa (1993) (62,7 e 61,4 cm), para machos e fêmeas da raça Mangalarga Marchador.

Comprimento da cabeça e do pescoço apresentaram valores médios e percentuais bastante similares, apesar de terem sido observados para comprimento do pescoço valores médios maiores a partir dos 6 meses, chegando à idade adulta quase $10 \mathrm{~cm}$ maior. 


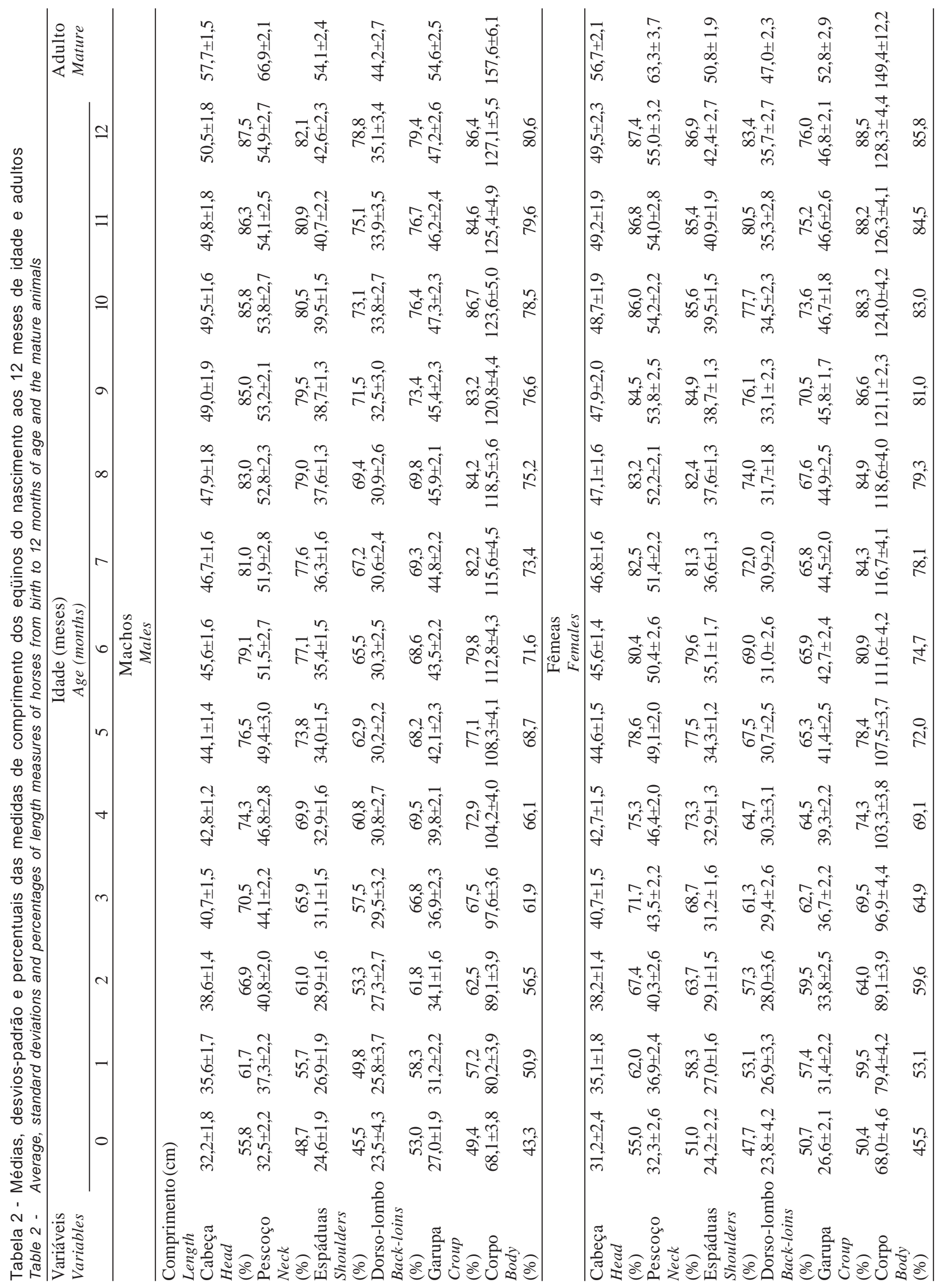

\section{R. Bras. Zootec., v.33, n.4, p.989-1000, 2004}


Segundo Borton (1979), a cabeça e o pescoço exercem papel importante na capacidade atlética do cavalo, pois a liberdade de movimento da cabeça e do pescoço influenciam a qualidade da marcha.

Os valores médios observados para comprimento das espáduas foram de 24,6; 35,4 e 42,6 cm, nos machos, e de 24,$2 ; 35,1$ e 42,4 cm, nas fêmeas, ao nascimento, aos 6 e 12 meses, respectivamente. Isso corresponde a 45,5 e 47,7\% da média à idade adulta, ao nascimento, e a 78,8 e 83,4\% da média à idade adulta, aos 12 meses, em machos e fêmeas, respectivamente, demonstrando que ainda ocorre crescimento considerável dos 12 meses à idade adulta. Os valores médios observados à idade adulta foram 54,1 e 50,8 cm, para machos e fêmeas, respectivamente.

Zamborlini (1996) observou valores médios de 54 e $51 \mathrm{~cm}$, para machos e fêmeas, respectivamente, e Lage (2001), de 59 e 62 cm para o comprimento das espáduas dos machos e das fêmeas adultos da raça Mangalarga Marchador, respectivamente. Os valores médios obtidos neste estudo para o comprimento do dorso-lombo foram de 23,5; 30,3 e 35,1 cm, nos machos e de 23,8; 31 e $35,7 \mathrm{~cm}$, nas fêmeas, ao nascimento, aos 6 e aos 12 meses de idade. Isso equivale a 53; 68,6 e 79,4\% do valor médio à idade adulta nos machos e a 50,7; 65,9 e 76\% do valor médio à idade adulta nas fêmeas, demonstrando que essa medida apresenta grande potencial de variação dos 12 meses à idade adulta.

Os valores observados para machos e fêmeas à idade adulta foram 44,2 e $47 \mathrm{~cm}$, respectivamente. Pode-se observar que, do nascimento à idade adulta, as fêmeas apresentaram maior comprimento de dorso-lombo que os machos. Barbosa (1993) obteve valores de 52,1 e 53,4 cm para machos e fêmeas adultos da raça Mangalarga Marchador; fato que pode estar relacionado ao maior rigor utilizado na avaliação dos machos para o registro genealógico e à maior pressão de seleção para o melhoramento genético a que os machos são submetidos.

O comprimento do dorso-lombo é uma medida importante que deve ser bem observada, uma vez que, por estar situado entre as partes anterior e posterior do corpo, influencia a proporcionalidade do animal. Deve-se ter cuidado na hora de mensurar o dorso-lombo, já que está diretamente ligado à conformação e ao comprimento da cernelha. Alguns animais possuem cernelha bem destacada e longa e outros, porém, cernelha pouco destacada, que pode induzir a erro na mensuração do dorso-lombo. Zamborlini(1996) observou que a medida linear de maior variabilidade entre os machos da raça Mangalarga Marchador foi o comprimento dorso-lombo.

O comprimento da garupa apresentou valores médios de 27,0; 43,5 e 47,2 cm nos machos e de 26,6; 42,7 e 46,8 cm nas fêmeas, ao nascimento, aos 6 e aos 12 meses de idade, respectivamente. Os percentuais em relação à idade adulta foram de 49,4; 79,8 e 86,4\% nos machos e 50,4; 80,9 e 88,5\% nas fêmeas, ao nascimento, aos 6 e aos 12 meses de idade, respectivamente, demonstrando rápido crescimento nos três primeiros meses e grande variação do nascimento aos 12 meses e dos 12 meses à idade adulta. Os machos adultos apresentaram valores médios de 54,6 cm e as fêmeas, de $47 \mathrm{~cm}$. Barbosa (1993) e Zamborlini (1996) observaram, respectivamente, valores de 52,6 e 52,2 cm e de 54 e $51 \mathrm{~cm}$, em machos e fêmeas.

Foram observados valores de comprimento do corpo de 68,1; 112,6 e 127,1 cm nos machos e 68; 111,6 e 128,3 cm, nas fêmeas, ao nascimento, aos 6 e aos 12 meses, respectivamente, e ganho médio de $44 \mathrm{~cm}$ do nascimento aos 6 meses e de 15,6 cm dos 6 aos 12 meses de idade. Resultados semelhantes foram obtidos por Rezende (1984), que observou, no período pósdesmama, ganho médio de $16 \mathrm{~cm}$ em potros da raça Mangalarga Marchador submetidos a dietas com três diferentes níveis de suplementação protéica.

Em relação à idade adulta, os valores observados para comprimento do corpo foram de 43,3; 71,6 e $86,6 \%$, nos machos, e de 45,$5 ; 74,7$ e $85,8 \%$, nas fêmeas, ao nascimento, aos 6 e aos 12 meses de idade, respectivamente. Reed \& Dunn (1977), avaliando o crescimento de potros da raça Árabe, verificaram que o comprimento do corpo foi a variável que apresentou maior taxa de crescimento, passando de $44,39 \%$, ao nascimento, para $90,69 \%$ do valor à idade adulta, aos 12 meses de idade, e que, à idade adulta, os machos foram maiores que as fêmeas em todas as características estudadas, exceto no comprimento do corpo, característica que apresentou maiores valores nas fêmeas adultas que nos machos.

Neste estudo, os machos adultos apresentaram valor médio para o comprimento do corpo de 157,6 cm e as fêmeas, de 149,4 cm. Esses valores foram superiores aos observados em machos e fêmeas adultos, por Zamborlini (1986), de 152 e $148 \mathrm{~cm}$, respectivamente, e por Barbosa (1993), de 150 e 147 cm, respectivamente.

Os valores médios e os desvios-padrão, bem como os percentuais em relação à média dos animais adultos, da largura da cabeça, do peito e das ancas,

\section{R. Bras. Zootec., v.33, n.4, p.989-1000, 2004}


dos machos e das fêmeas, do nascimento aos 12 meses de idade, podem ser observados na Tabela 3.

Os valores médios obtidos para largura da cabeça foram de 13,0; 17,3 e 18,7 cm, nos machos, e 13,1; 17,3 e $18,7 \mathrm{~cm}$, nas fêmeas, enquanto nos animais adultos, de 21,3 e $21,9 \mathrm{~cm}$, em machos e fêmeas, respectivamente. Zamborlini (1996) observou o mesmo valor de $20 \mathrm{~cm}$ para ambos machos e fêmeas adultos da raça Mangalarga Marchador. Barbosa (1993) observou valores de 20,7 e 20,3 cm, para machos e fêmeas da mesma raça, respectivamente.

A largura da cabeça apresenta variação muito pequena, pois os animais já nascem com 60,9 e 59,6\% do valor médio à idade adulta e chegam aos 12 meses com 87,8 e 85,2\% do valor médio à idade adulta, em machos e fêmeas, respectivamente.

Os valores médios observados para largura do peito foram de 18,4; 27,8 e 29,7 cm e de 18,0; 27,4 e $30,0 \mathrm{~cm}$ em machos e fêmeas e para largura das ancas, de 18,4; 32,6 e 38,8 cm nos machos e de 18,6; 32,6 e 39, $1 \mathrm{~cm}$ nas fêmeas, ao nascimento, aos 6 e aos 12 meses, respectivamente.

Esses dados demonstram que, ao nascimento, os valores de largura do peito e das ancas são similares, porém, aos seis meses, os valores de largura das ancas já são bem superiores aos do peito. Isso pode ser comprovado pela diferença entre as duas variáveis no percentual do nascimento em relação à idade adulta, que foi de 36,4 e 37,6\%, nos machos e nas fêmeas, respectivamente, para largura das ancas. Os valores observados para largura do peito, ao nascimento, são de 45,2 e $50,1 \%$ em machos e fêmeas, respectivamente.

Em animais adultos, os valores médios observados para largura das ancas de machos e fêmeas foram de 49,4 e 50,7 cm, respectivamente. Zamborlini (1996) observou respectivos valores de 51 e $50 \mathrm{~cm}$ para a largura das ancas, de machos e fêmeas adultos da raça Mangalarga Marchador.

Os valores médios, desvios-padrão e percentuais, em relação à média dos animais adultos, das distâncias espádua-boleto, codilho-solo, codilho-joelho, joelhoboleto, soldra-jarrete e jarrete-boleto, de machos e fêmeas do nascimento aos 12 meses de idade podem ser observados na Tabela 4.

As medidas de distância apresentaram pequena variação do nascimento à idade adulta, corroborada pelos valores médios percentuais que, ao nascimento, eram superiores a $60 \%$ e aos 12 meses já ultrapassavam os $90 \%$ da média à idade adulta, demonstrando alta taxa de desenvolvimento no período de gestação.
Os valores observados para distância ponta da espádua ao boleto foram de 58,7; 76,3 e 83,1 cm, nos machos e de 58,2; 75,1 e 82 cm nas fêmeas, respectivamente, ao nascimento, aos 6 e aos 12 meses de idade. Thompson (1995), avaliando o crescimento de potros da raça PSI, obteve valores de 70,4; 82,3 e 88,1 cm, nos machos e 69,6; 82,6 e 89,7 cm, nas fêmeas, ao nascimento, aos 6 e aos 12 meses de idade, respectivamente.

A distância ponta da espádua ao boleto foi a que apresentou maiores valores de crescimento, com ganho médio de 24,4 cm nos machos e 23,8 cm nas fêmeas e percentuais médios de 67 e 94,5\% da distância à idade adulta, ao nascimento e aos 12 meses de idade, respectivamente.

Pode-se observar que a distância codilho-solo apresenta menor variação, do nascimento à idade adulta, se comparada à distância espádua-boleto, porém, apesar de apresentar médias superiores em todas as idades, a diferença entre as duas diminui em função do crescimento, chegando à idade adulta com apenas 2,3 e 1,1 cm de diferença, nos machos e nas fêmeas, respectivamente. As distâncias codilho-joelho e soldra-jarrete, que caracterizam o comprimento do antebraço e da perna, respectivamente, foram as que apresentaram menores percentuais em relação à idade adulta, tanto ao nascimento quanto aos 12 meses de idade, demonstrando menor precocidade e maior variação que as distâncias joelho-boleto e jarrete-boleto, que caracterizam o comprimento da canela nos membros anteriores e posteriores.

A distância joelho-boleto foi a que apresentou menores valores médios de crescimento, do nascimento aos 12 meses de idade, crescendo apenas $4 \mathrm{~cm}$ nos machos e 3,7 cm nas fêmeas, com percentuais médios de 84,5 e 97,6\% em relação à idade adulta, ao nascimento e aos 12 meses, respectivamente.

A distância jarrete-boleto apresentou crescimento de 7,2 e 7,1 cm, em machos e fêmeas, do nascimento aos 12 meses de idade, com percentuais em relação à idade adulta de 79,8 e 100,3\%, nos machos, e de 78,3 e 98,7\%, nas fêmeas. Segundo Kruger (1939), citado por Santos (1989), o crescimento dos ossos metacarpo e metatarso se completa no final do primeiro ano de idade; dos ossos digital, rádio, tíbia e perônio, no segundo ano; e os demais crescem até o terceiro e quarto ano de idade.

Os valores médios, desvios-padrão e percentuais, em relação à média dos animais adultos, dos perímetros de tórax, antebraço, joelho, canela e boleto, de machos e fêmeas do nascimento aos 12 meses de idade podem ser observados na Tabela 5 .

R. Bras. Zootec., v.33, n.4, p.989-1000, 2004 


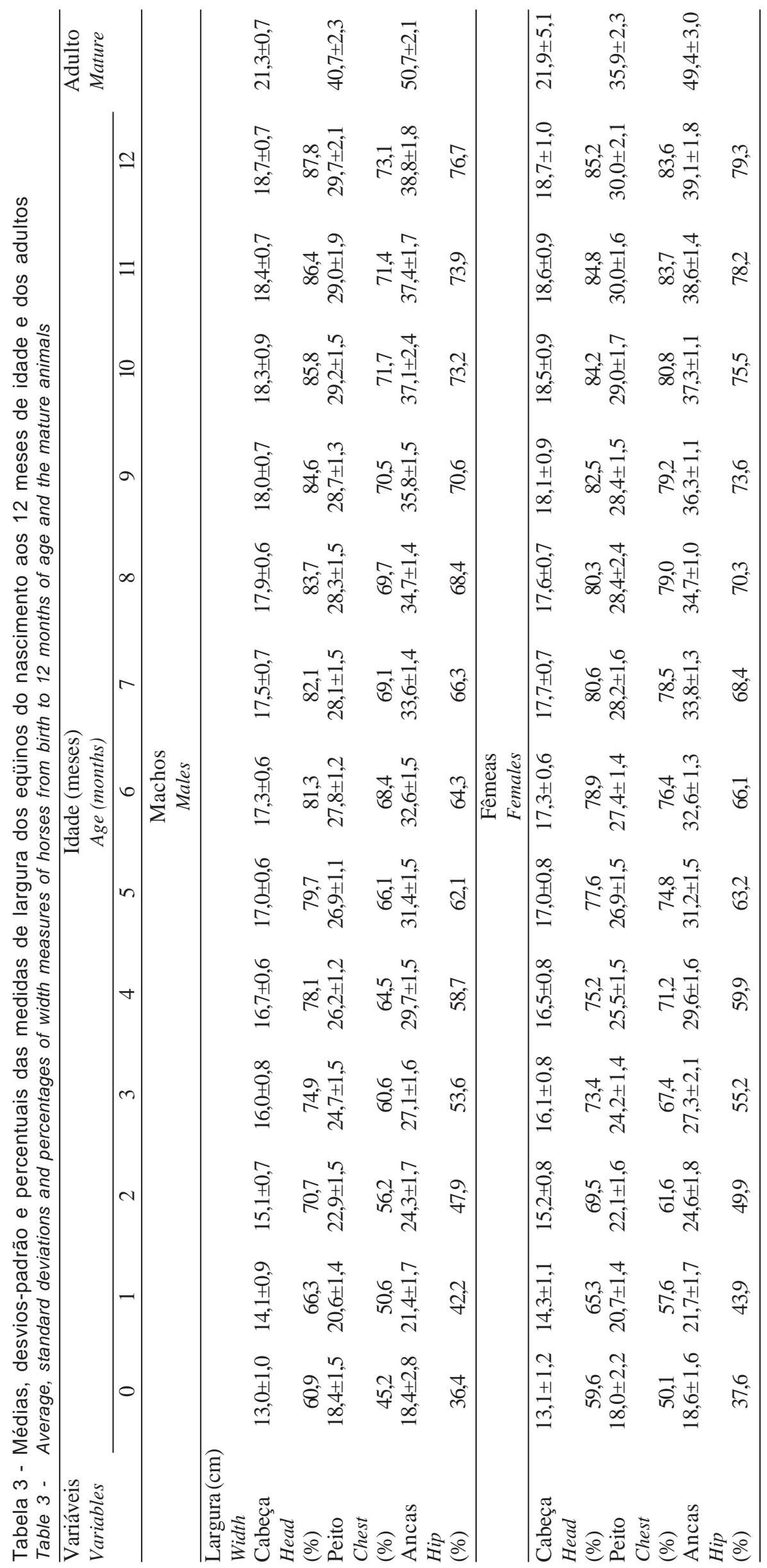




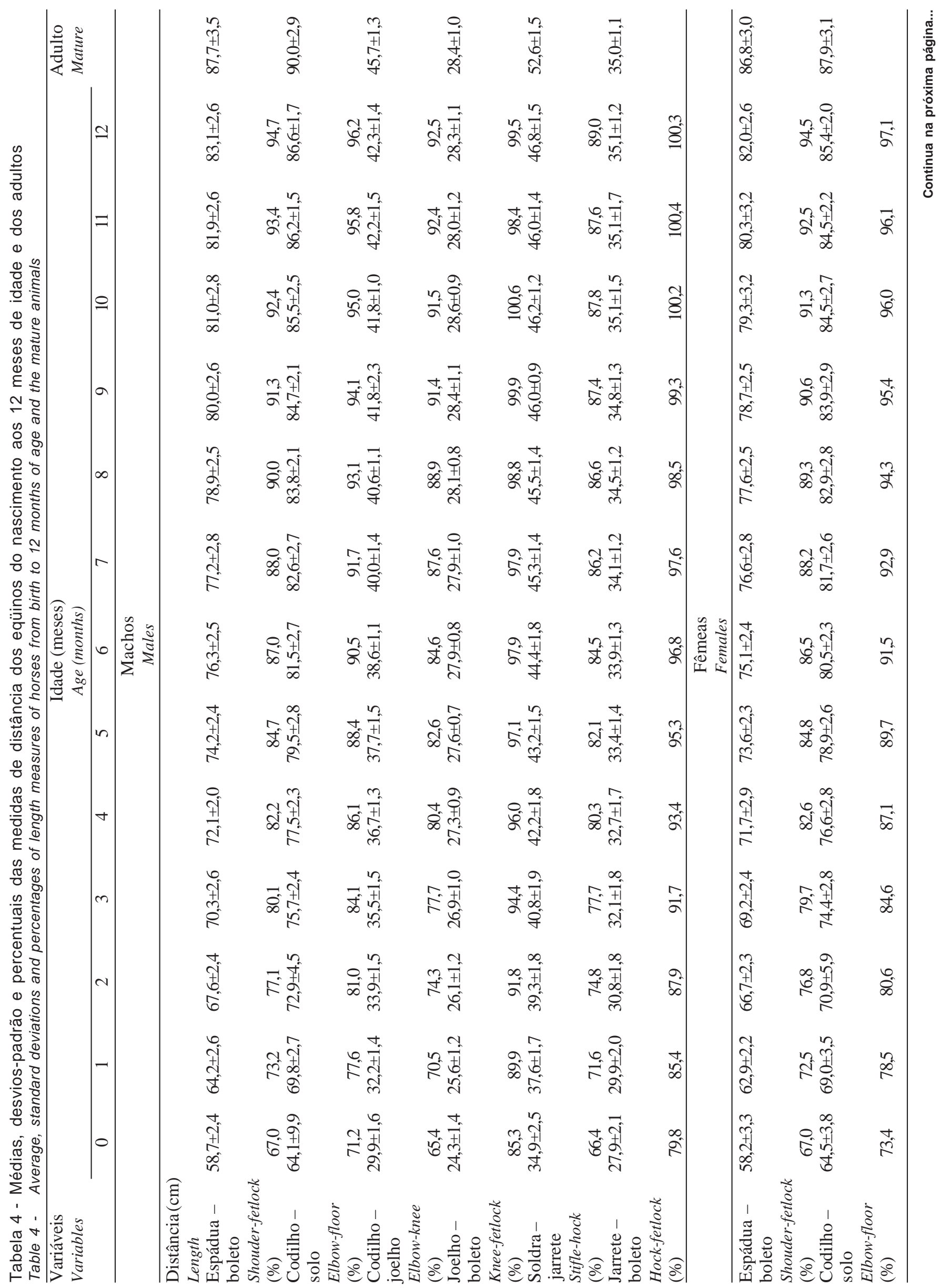




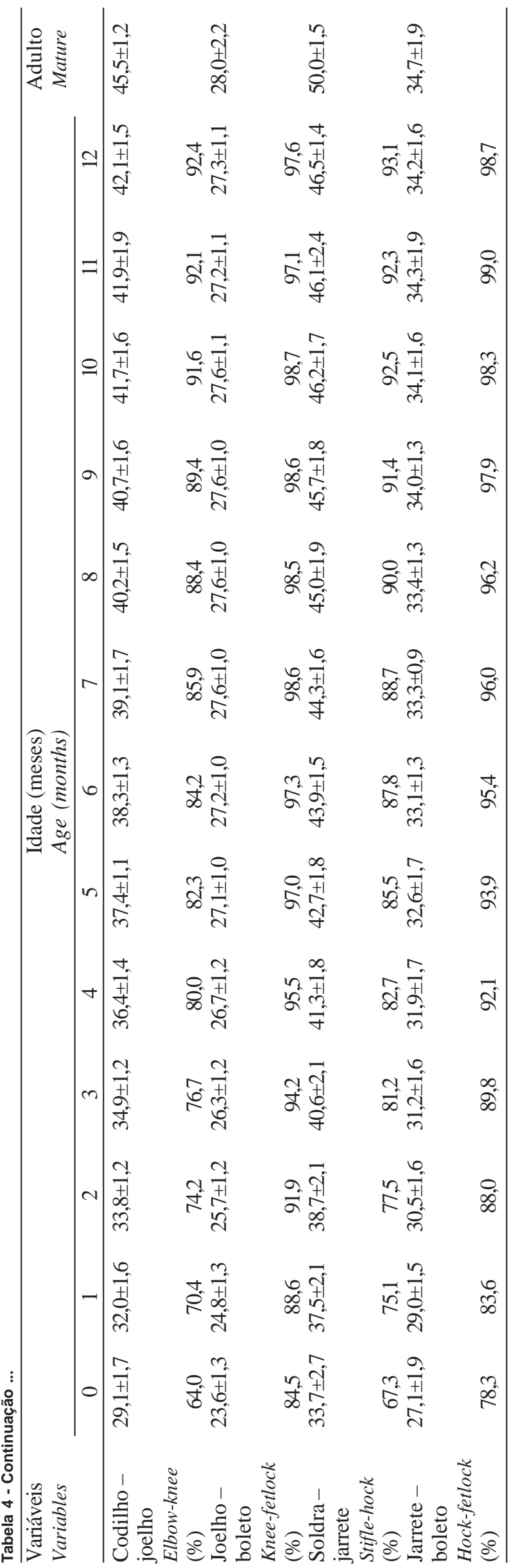

Os valores médios de 83,7; 128,6 e 143,2 cm nos machos e de 82,6; 129,4 e 145,4 cm nas fêmeas, observados para o perímetro torácico, demonstram que os machos nascem, em média, com perímetro torácico maior que as fêmeas e chegam aos 12 meses com valores inferiores, porém à idade adulta superam as fêmeas em quase $5 \mathrm{~cm}$. Os valores médios, aos 6 e aos 12 meses, obtidos neste estudo foram superiores aos de 125,7 e 142,8 cm aos 7 e 12,7 meses de idade, respectivamente, observados por Rezende (1984), em potros da raça Mangalarga Marchador.

Porte (2000) observou, em cavalos Crioulos Chilenos, que ao nascimento os machos apresentaram valor médio de perímetro torácico de $74,5 \mathrm{~cm}$, levemente superior ao das fêmeas (73,8 cm), porém, a partir dos 18 meses até os três anos, as fêmeas mantiveram superioridade de $2 \%$ sobre os machos.

Constata-se, pelos valores percentuais em relação à idade adulta, ao nascimento, aos 6 e aos 12 meses, de 46,$3 ; 71,1$ e 79,2\% nos machos e de 47 ; 73,6 e $82,8 \%$ nas fêmeas, que o perímetro torácico apresentou grande variação do nascimento aos 12 meses e dos 12 meses à idade adulta.

Os valores dos percentuais em relação à idade adulta, observados para o perímetro do antebraço de 50,9 e 78,1\% nos machos e 52,5 e 82,3\% nas fêmeas, ao nascimento e aos 12 meses, respectivamente, demonstram que esta variável também apresenta grande variação até os 12 meses e, principalmente, dos 12 meses à idade adulta, já que o aumento do perímetro do antebraço é influenciado pelo aumento da musculatura, que será mais intenso a partir da puberdade.

O perímetro da canela é uma variável bem estudada, provavelmente em função da preocupação com a qualidade óssea dos animais. Os valores médios observados para o perímetro da canela, de 11,9; 16,1 e $17,3 \mathrm{~cm}$ nos machos e 11,$6 ; 15,8$ e $16,9 \mathrm{~cm}$ nas fêmeas, são similares aos encontrados por Rezende et al. (1997), em potros Mangalarga Marchador, de 12,1 e 16,7 cm, aos 40 e 365 dias de idade.

Zamborlini (1996) observou que ambos machos e fêmeas adultos da raça Mangalarga Marchador apresentaram valor médio de $18 \mathrm{~cm}$ para o perímetro da canela, enquanto Barbosa (1993) verificou valores médios respectivos de 18,7 e 17,9 cm, para machos e fêmeas adultas da mesma raça. Neste estudo, os valores do perímetro da canela nos animais adultos foram 19,7 e 19,0 cm, para machos e fêmeas, respectivamente. 


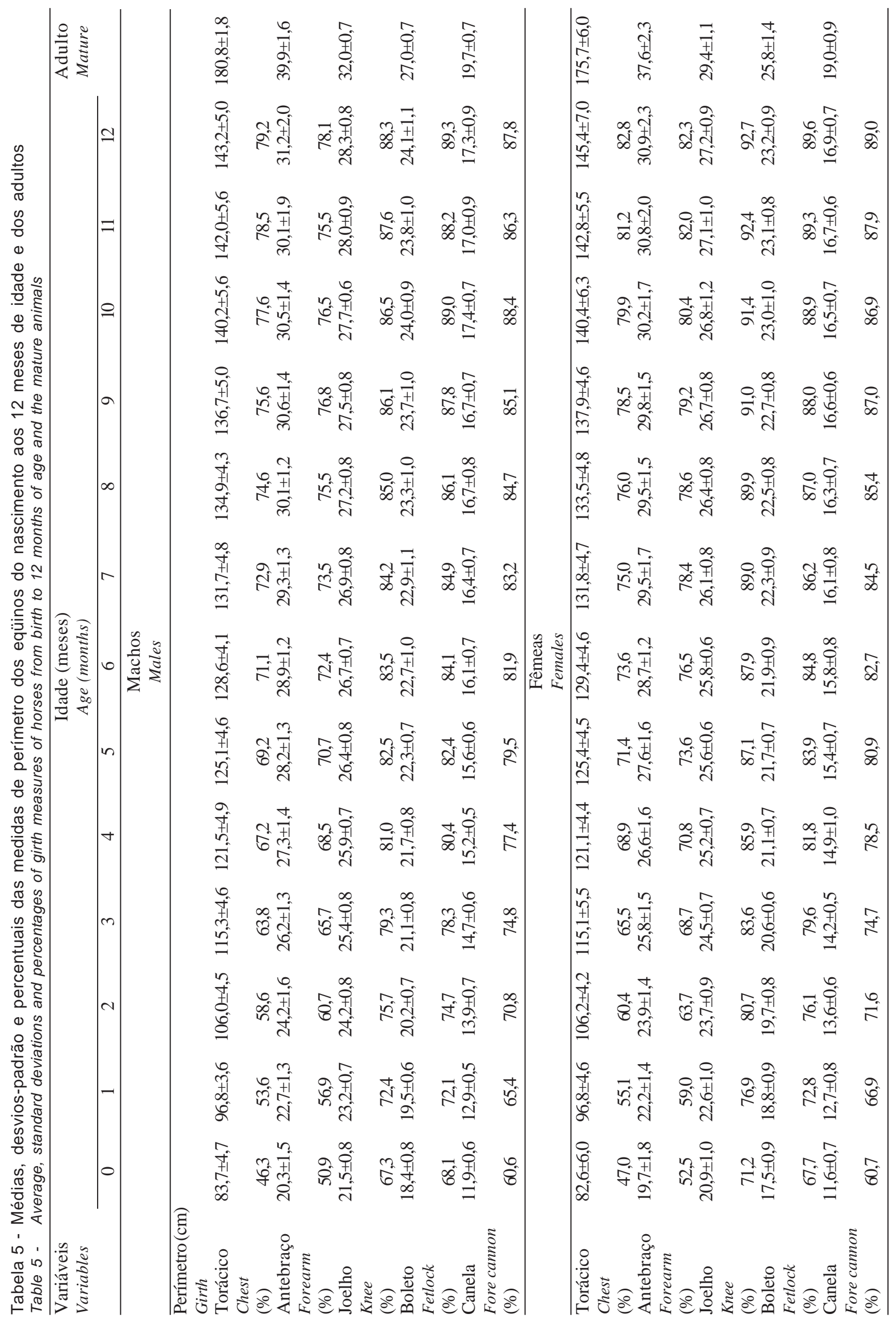

\section{R. Bras. Zootec., v.33, n.4, p.989-1000, 2004}




\section{Conclusões}

As medidas de altura, comprimento do corpo e perímetro torácico avaliadas no período do nascimento aos 12 meses de idade podem ser consideradas eficientes parâmetros para análise do crescimento dos eqüinos. Todavia, outras medidas como as distâncias joelhoboleto e jarrete-boleto e a largura da cabeça, que apresentaram pequena variação do nascimento aos 12 mese de idade, podem ser importantes ferramentas para a avaliação e a seleção fenotípica de animais jovens.

\section{Agradecimento}

À FAPERJ e à ABCCMM, pelo apoio financeiro, e aos proprietários dos criatórios participantes do experimento, por disponibilizarem seus animais: Haras FB Arpoador, localizado em Jesuítas, Rio de Janeiro, RJ; Haras do Corumbá, localizado em Morro Azul, Vassouras, RJ; Fazenda Paraíso; Haras JDB; Haras Jequitibá; Haras da Catimba e Haras Fomento, localizados em Sacra Família do Tinguá, Engenheiro Paulo de Frontin, RJ.

\section{Literatura Citada}

\section{ASSOCIAÇÃO BRASILEIRA DOS CRIADORES DO CAVALO} MANGALARGA MARCHADOR - ABCCMM. Estatuto. Belo Horizonte: O Lutador, 1992. 89p.

BARBOSA, C.G. Estudo morfométrico na raça Mangalarga Marchador. Uma abordagem multivariada. Belo Horizonte: Universidade Federal de Minas Gerais, 1993. 76p. Dissertação (Mestrado em Zootecnia) - Universidade Federal de Minas Gerais, 1993.

BORTON, A. Biologia del caballo. In: HINTZ, H. F.; EVANS, J.W.; BORTON, A. et al. (Eds.) El caballo. Zaragoza: Acribia, 1979. p.233-334.

BRITO, A.A. Avaliação e mensuração. Curso de capacitação de técnicos e árbitros da raça Mangalarga Marchador. Belo Horizonte: ABCCMM, 1990. 132p.

CAMARGO, M.X.; CHIEFFI, A. Ezoognósia. São Paulo: CPA/ Intituto de Zootecnia, 1971. 320p.

HINTZ, H.F.; HINTZ, R.L.; Van VLECK, L.D. Growth rate of Thoroughbreds. Effect of age of dam, year and month of birth, and sex of foal. Journal of Animal Science, v.48, n.3, p.480-487, 1979.
JORDÃO, L.P.; CAMARGO, M.X. Estudo sobre algumas medidas do cavalo Mangalarga criado na Coudelaria Paulista. Boletim da Indústria Animal, v.11, p.81-95, 1950.

LAGE, M.C.G.R. Caracterização morfométrica, dos aprumos e do padrão de deslocamento de eqüinos da raça Mangalarga Marchador e suas associações com a qualidade da marcha. Belo Horizonte: Universidade Federal de Minas Gerais, 2001. 114p. Tese (Doutorado em Ciência Animal) - Universidade Federal de Minas Gerais, 2001.

PORTE, E.F. Crescimento y desarrollo del caballo Criollo Chileno. Avances en Producion Animal, v.25, n.1/2, p.167- 174, 2000.

REED, K.R.; DUNN, N.K. Growth and development of the Arabian horse. In: EQUINE NUTRITION AND PHISIOLOGY SYMPOSIUM, 5., 1977. St. Louis - MO. Proceedings... Columbia: Equine Nutrition and Physiology Society and University of Missouri, 1977. p.76-98.

REZENDE, A.S.C. Efeito do nível do concentrado suplementar sobre o crescimento de potros pós-desmama.Belo Horizonte: Universidade Federal de Minas Gerais, 1984. 32p. Dissertação (Mestrado em Zootecnia) - Universidade Federal de Minas Gerais, 1984

REZENDE, A.S.C.; SAMPAIO, I.B.M.; LEGORRETA, G.L. et al. Avaliação do desenvolvimento corporal de potros Mangalarga Marchador submetidos a dois diferentes programas nutricionais. In: REUNIÃO ANUAL DA SOCIEDADE BRASILEIRA DE ZOOTECNIA, 34., 1997, Juiz de Fora. Anais... Juiz de Fora: Sociedade Brasileira de Zootecnia, 1997. p.171-174.

SANTOS, S.A. Estudo sobre algumas características de crescimento de cavalos Brasileiro de Hipismo produzidos no Haras Pioneiro. Piracicaba: Escola Superior de Agricultura Luiz de Queiroz, 1989. 91p. Dissertação (Mestrado em Agronomia: Nutrição Animal e Pastagens) Escola Superior de Agricultura Luiz de Queiroz, 1989.

STATISTICAL ANALYSES SYSTEM - SAS. User's guide: statistical. version 6. The NLIN procedure. Cary: 1996.

THOMPSON, K.N. Skeletal growth rates of weanling and yearling Thoroughbred horses. Journal of Animal Science, v.73, p.2513-2517, 1995.

ZAMBORLINI, L.C. Estudo genético quantitativo das medidas lineares da raça Mangalarga Marchador. Belo Horizonte: Universidade Federal de Minas Gerais, 1996. 47p. Tese (Doutorado em Ciência Animal) Universidade Federal de Minas Gerais, 1996. 